\title{
Favipiravir: insight into the crystal structure, Hirshfeld surface analysis and computational study
}

\author{
Maria G. Babashkina ${ }^{1}$ - Antonio Frontera ${ }^{2}$ - Alexander V. Kertman ${ }^{3}$ - Yasemin Saygideger ${ }^{4,5}$. \\ Swaminathan Murugavel ${ }^{6} \cdot$ Damir A. Safin ${ }^{3,7,8}$ (1)
}

Received: 11 March 2021 / Accepted: 12 May 2021 / Published online: 9 June 2021

(c) Iranian Chemical Society 2021

\begin{abstract}
In this work we report structural and computational studies of favipiravir, which is now used as a drug for COVID-19 treatment. The molecule is completely flat and stabilized by an intramolecular $\mathrm{O}-\mathrm{H} \cdots \mathrm{O}$ hydrogen bond, yielding a six-membered pseudo-aromatic ring. The aromaticity index of this pseudo-aromatic ring was found to be 0.748 , while the same indix for the pyrazine ring in favipiravir was found to be 0.954 . The crystal packing of favipiravir is mainly constructed through intermolecular $\mathrm{N}-\mathrm{H} \cdots \mathrm{O}, \mathrm{N}-\mathrm{H} \cdots \mathrm{N}$ and $\mathrm{C}-\mathrm{H} \cdots \mathrm{O}$ hydrogen bonds, yielding a 3D supramolecular framework with a zst topology defined by the point symbol of $\left(6^{5} \cdot 8\right)$. The crystal structure of favipiravir is further stabilized by weak C-F $\cdots \mathrm{F}-\mathrm{C}$ intermolecular type II dihalogen interactions, yielding a 1D supramolecular polymeric chain. More than $80 \%$ of the total Hirshfeld surface area for favipiravir is occupied by $\mathrm{H} \cdots \mathrm{H} / \mathrm{C} / \mathrm{N} / \mathrm{O} / \mathrm{F}$ and $\mathrm{C} \cdots \mathrm{N} / \mathrm{O}$ contacts. Energy frameworks have been calculated to additionally analyze the overall crystal packing. It was established that the structure of favipiravir is mainly characterized by the dispersion energy framework followed by the less significant electrostatic energy framework contribution. Finally, by using density functional theory (DFT) calculations and the quantum theory of atoms in molecules, we have assigned the interaction energy of each hydrogen bond, which can be helpful to develop scoring functions to be used in force fields/docking calculations.
\end{abstract}

Keywords Favipiravir $\cdot$ Crystal structure $\cdot$ Hirshfeld surface analysis $\cdot$ Computational study $\cdot$ DFT

Damir A. Safin

damir.a.safin@gmail.com

1 Institute of Condensed Matter and Nanosciences, Université Catholique de Louvain, Place L. Pasteur 1, 1348 Louvain-la-Neuve, Belgium

2 Departament de Química, Universitat de Les Illes Balears, Crta de Valldemossa km 7.5, 07122 Palma de Mallorca (Baleares), Spain

3 University of Tyumen, Volodarskogo Str. 6, 625003 Tyumen, Russian Federation

4 Department of Biotechnology, Institute of Natural and Applied Sciences, Çukurova University, Adana, Turkey

5 Department of Pulmonary, School of Medicine, Cukurova University, Adana, Turkey

6 Department of Physics, Thanthai Periyar Government Institute of Technology, Vellore 632002, Tamil Nadu, India

7 Kurgan State University, Sovetskaya Str. 63/4, 640020 Kurgan, Russian Federation

8 Innovation Center for Chemical and Pharmaceutical Technologies, Ural Federal University named after the First President of Russia B.N. Eltsin, Mira Str. 19, 620002 Ekaterinburg, Russian Federation

\section{Introduction}

These days humanity is in dire need of drugs for COVID19 treatment. Of these drugs, favipiravir (Fig. 1) [1-3] also known as T-705, avigan (abigan), avifavir, areplivir, fabiflu, favipira and favilavir, was recently found as a drug in the treatment of SARS-CoV-2 [4, 5]. Obviously, as deeper researchers can understand different properties of favipiravir as a more powerful weapon it might be in this bloody war with viruses.

With all this in mind as well as in continuation of our ongoing interest in crystal structures studies, especially those comprising a myriad of non-covalent interactions, we have directed our attention to the crystal structure of favipiravir. A comprehensive search in the Cambridge Structural Database (CSD) [6] revealed only one hit for favipiravir (CCDC number 969968) [7], and the corresponding CIF file was substracted from the CSD for an in-depth analysis (vide infra) of its crystal structure.

In this work, we shed more light on the crystal structure of favipiravir using Hirshfeld surface analysis to in-depth 


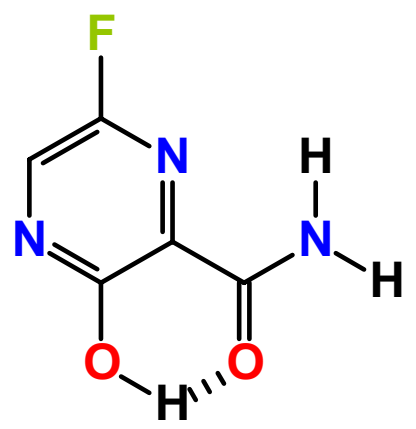

Fig. 1 Diagram of favipiravir

examine non-covalent interactions responsible for crystal packing. Furthermore, energy frameworks have been calculated to analyse the overall crystal packing of favipiravir. Moreover, this molecule presents several hydrogen bond donor and acceptor sites that are expected to be crucial in its interaction with proteins. In fact, it exhibits a variety of $\mathrm{N}-\mathrm{H} \cdots \mathrm{N}$ and $\mathrm{N}-\mathrm{H} \cdots \mathrm{O}$ interactions in the solid state that have been evaluated using density functional theory (DFT) calculations and the quantum theory of atoms-inmolecules (QTAIM). These energetic values can be useful to develop scoring functions for docking studies and force field parameters.

\section{Experimental}

\section{Theoretical methods}

The calculations of non-covalent interactions were performed using Gaussian-16 [8] at the PBE0-D3/def2-TZVP level of theory. The energies have been corrected using the Boys and Bernardi counterpoise method [9]. The Grimme's D3 dispersion correction has been used in the calculations [10]. To evaluate the interactions in the solid state, the crystallographic coordinates were used and only the position of the hydrogen bonds has been optimized. This procedure and level of theory has been used before to investigate noncovalent interactions in the solid state $[11,12]$. The interaction energies were computed by calculating the difference between the energies of the isolated monomers and the ones of their assembly. The QTAIM analysis [13] and NCIplot index [14] have been computed at the same level of theory by means of the AIMAll program [15].

\section{Results and discussion}

According to single-crystal X-ray diffraction, favipiravir crystallizes in the orthorhombic space group Pna2 $2_{1}$ with one independent molecule in the asymmetric unit (Fig. 2).
All the bond lengths, bond and dihedral angles are typical yielding an almost planar structure (Table 1). The structure of favipiravir is stabilized by an intramolecular hydrogen bond, formed between the hydroxyl hydrogen atom and the carbonyl oxygen atom (Fig. 2, Table 2). As a result of this intramolecular hydrogen bonding the six-membered pseudoaromatic ring [16] is formed. This ring is constructed from five covalent bonds and one non-covalent bond (Fig. 2), which is accompanied by certain conjugation effects and has a certain degree of covalency [17]. This is the case of the resonance-assisted hydrogen bonding (RAHB), where the donor and acceptor are connected by a $\pi$-conjugated system [18]. The aromaticity index of this pseudo-aromatic ring was found to be 0.748 , as evidenced from the Harmonic Oscillator Model of Aromaticity for Heterocycle Electron Delocalization (HOMHED) [19]. Using the same approach the aromaticity index for the pyrazine ring in favipiravir was found to be 0.954 . Furthermore, the crystal structure of favipiravir is additionaly stabilized by intermolecular $\mathrm{N}-\mathrm{H} \cdots \mathrm{O}$, $\mathrm{N}-\mathrm{H} \cdots \mathrm{N}$ and $\mathrm{C}-\mathrm{H} \cdots \mathrm{O}$ hydrogen bonds (Fig. 2, Table 2). As a result of intermolecular hydrogen bonds, molecules of favipiravir are packed into a 3D supramolecular framework (Fig. 3). This 3D supramolecular framework was simplified, using the ToposPro software [20], resulting in a zst topology defined by the point symbol of $\left(6^{5} \cdot 8\right)$ (Fig. 3). Notably, the crystal structure of favipiravir is further stabilized by weak $\mathrm{C}-\mathrm{F}$...F-C intermolecular type II dihalogen interactions (Fig. 2, Table 2) [21-23]. The F...F distances 3.067(3) ^ are verys similar to the sum of two van der Waals radii for fluorine $(\sim 1.50 \AA)$ [24]. As a result of intermolecular dihalogen interactions, molecules of favipiravir are packed into a 1D supramolecular polymeric chain (Fig. 2).

To shed more light on the crystal packing of favipiravir, we have further applied a Hirshfeld surface analysis [25], reflected in a set of corresponding 2D fingerprint plots [26]. The latter were generated using CrystalExplorer 17 [27]. Furthermore, the enrichment ratios $(E)$ [28] of the intermolecular contacts were also calculated to estimate the propensity of two chemical species to be in contact.

We have first generated a Hirshfeld surface of favipiravir calculated over $d_{\text {norm }}$. The resulting surface contains five bright red spots (Fig. 4), corresponding to donors and acceptors of the above mentioned intermolecular $\mathrm{N}-\mathrm{H} \cdots \mathrm{O}$, $\mathrm{N}-\mathrm{H} \cdots \mathrm{N}$ and $\mathrm{C}-\mathrm{H} \cdots \mathrm{O}$ hydrogen bonds (Fig. 2, Table 2). The donors and the acceptors of intermolecular $\mathrm{N}-\mathrm{H} \cdots \mathrm{O}$, $\mathrm{N}-\mathrm{H} \cdots \mathrm{N}$ and $\mathrm{C}-\mathrm{H} \cdots \mathrm{O}$ interactions can be evidenced as blue and red regions around the participating atoms on the Hirshfeld surface mapped over shape index (Fig. 4). Furthermore, no flat regions were observed on the Hirshfeld surface mapped over curvedness, testifying to the absence of reasonable $\pi \cdots \pi$ interactions between the six-membered rings (Fig. 4). 
Fig. 2 (top) Crystal structure of favipiravir. (bottom) 1D supramolecular polymeric chain, formed through $\mathrm{C}-\mathrm{F} \cdots \mathrm{F}-\mathrm{C}$ halogen bonds. Color code: $\mathrm{H}=$ black, $\mathrm{C}=$ gold, $\mathrm{N}=$ blue, $\mathrm{O}=$ red, $\mathrm{F}=$ green; $\mathrm{N}-\mathrm{H} \cdots \mathrm{O} / \mathrm{N}$, $\mathrm{O} / \mathrm{C}-\mathrm{H} \cdots \mathrm{O}$ and $\mathrm{C}-\mathrm{F} \cdots \mathrm{F}-\mathrm{C}$ interactions $=$ dashed cyan line
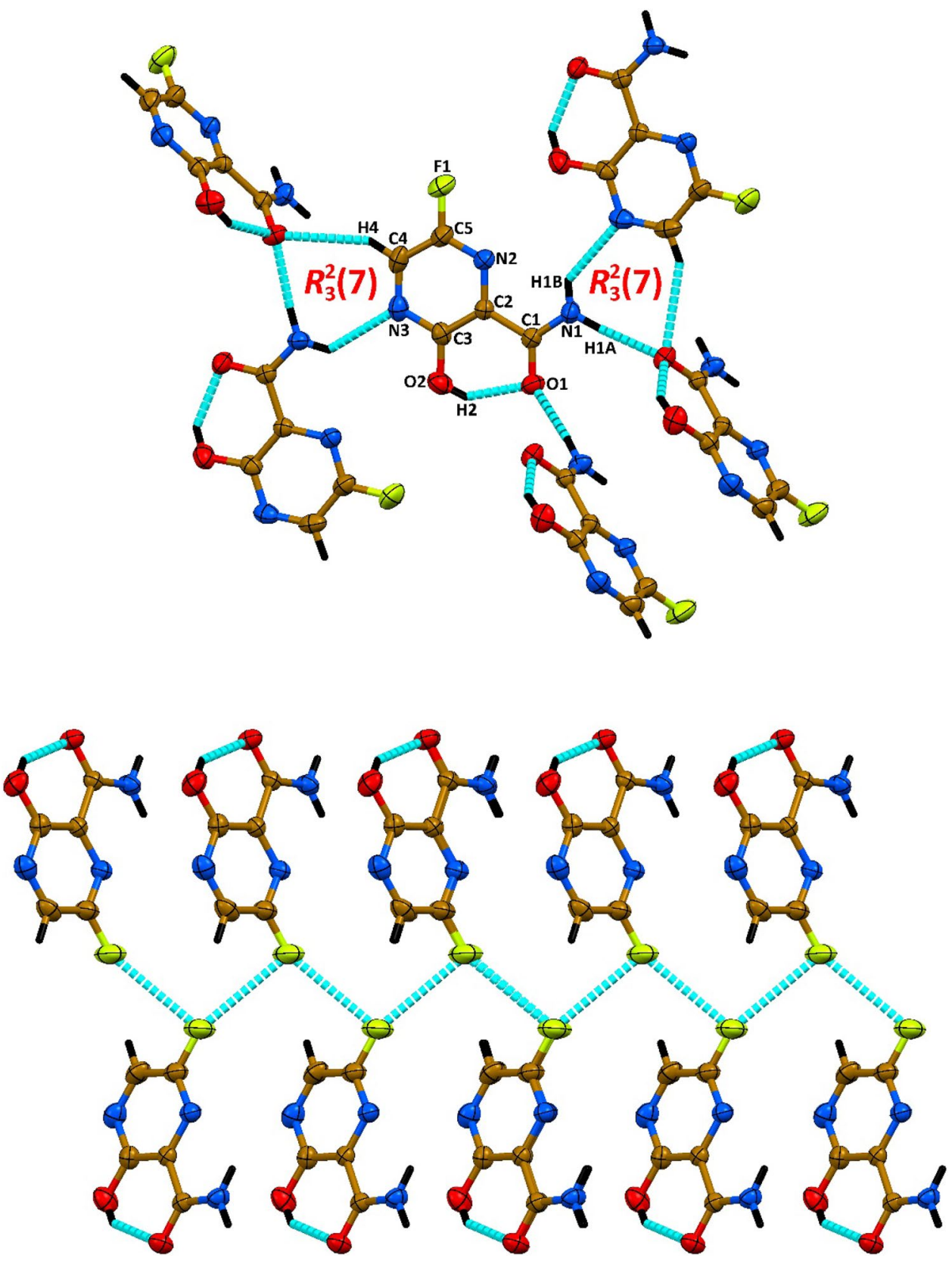

To study intermolecular interactions in details as well as their proportions on the Hirshfeld surface, corresponding $2 \mathrm{D}$ fingerprint plots were generated. It was found that intermolecular $\mathrm{H} \cdots \mathrm{H} / \mathrm{C} / \mathrm{N} / \mathrm{O} / \mathrm{F}$ and $\mathrm{C} \cdots \mathrm{N} / \mathrm{O}$ contacts, comprising about $82 \%$, are main contributors to the total Hirshfeld surface (Fig. 5, Table 3). Notably, the $\mathrm{H} \cdots \mathrm{N}$ and $\mathrm{H} \cdots \mathrm{O}$ contacts each are shown in the corresponding fingerprint plots as two sharp spikes with the shortest values at $d_{\mathrm{e}}+d_{\mathrm{i}} \approx 2.3 \AA$ and $2.0 \AA$, respectively (Fig. 5), corresponding to the above described $\mathrm{N}-\mathrm{H} \cdots \mathrm{N}$ and $\mathrm{N}-\mathrm{H} \cdots \mathrm{O}$ hydrogen bonds (Table 2). The $\mathrm{H} \cdots \mathrm{O} / \mathrm{F}, \mathrm{C} \cdots \mathrm{N} / \mathrm{O}$ and $\mathrm{F} \cdots \mathrm{F}$ contacts in the structure of favipiravir are highly favoured since the corresponding enrichment ratios $E_{\mathrm{HC} / \mathrm{F}}, E_{\mathrm{CN} / \mathrm{O}}$ and $E_{\mathrm{FF}}$ are larger than unity (Table 3$)$. This is explained by a relatively higher proportion of these contacts on the total Hirshfeld surface area over a corresponding proportion of random contacts $R_{\mathrm{HC} / \mathrm{F}}$, $R_{\mathrm{CN} / \mathrm{O}}$ and $R_{\mathrm{FF}}$, respectively (Table 3 ). The $\mathrm{H} \cdots \mathrm{H} / \mathrm{C} / \mathrm{N}, \mathrm{N} \cdots \mathrm{O}$ and $\mathrm{O} \cdots \mathrm{F}$ contacts are less favoured since the corresponding 
Table 1 Selected bond lengths $(\AA)$ and angles $\left(^{\circ}\right)$ in the structure of favipiravir

\begin{tabular}{|c|c|c|c|}
\hline \multicolumn{4}{|l|}{ Bond lengths } \\
\hline $\mathrm{C} 1-\mathrm{C} 2$ & $1.481(2)$ & $\mathrm{C} 3-\mathrm{O} 2$ & $1.328(2)$ \\
\hline $\mathrm{C} 1-\mathrm{N} 1$ & $1.318(2)$ & $\mathrm{C} 4-\mathrm{C} 5$ & $1.390(3)$ \\
\hline $\mathrm{C} 1-\mathrm{O} 1$ & $1.244(2)$ & C4-N3 & $1.306(3)$ \\
\hline $\mathrm{C} 2-\mathrm{C} 3$ & $1.397(2)$ & $\mathrm{C} 5-\mathrm{N} 2$ & $1.295(2)$ \\
\hline $\mathrm{C} 2-\mathrm{N} 2$ & $1.335(2)$ & C5-F1 & $1.339(3)$ \\
\hline $\mathrm{C} 3-\mathrm{N} 3$ & $1.340(2)$ & & \\
\hline \multicolumn{4}{|l|}{ Bond angles } \\
\hline $\mathrm{C} 1-\mathrm{C} 2-\mathrm{C} 3$ & $120.68(14)$ & $\mathrm{C} 3-\mathrm{N} 3-\mathrm{C} 4$ & $117.02(18)$ \\
\hline $\mathrm{C} 1-\mathrm{C} 2-\mathrm{N} 2$ & $117.97(15)$ & $\mathrm{C} 4-\mathrm{C} 5-\mathrm{N} 2$ & $123.30(19)$ \\
\hline $\mathrm{C} 2-\mathrm{C} 1-\mathrm{N} 1$ & $117.26(14)$ & C4-C5-F1 & $119.87(17)$ \\
\hline $\mathrm{C} 2-\mathrm{C} 3-\mathrm{N} 3$ & $120.84(16)$ & $\mathrm{C} 5-\mathrm{C} 4-\mathrm{N} 3$ & $121.22(18)$ \\
\hline $\mathrm{C} 2-\mathrm{C} 1-\mathrm{O} 1$ & $119.66(15)$ & $\mathrm{N} 1-\mathrm{C} 1-\mathrm{O} 1$ & $123.07(15)$ \\
\hline $\mathrm{C} 2-\mathrm{C} 3-\mathrm{O} 2$ & $123.53(15)$ & N2-C5-F1 & $116.8(2)$ \\
\hline $\mathrm{C} 2-\mathrm{N} 2-\mathrm{C} 5$ & $116.26(18)$ & $\mathrm{N} 3-\mathrm{C} 3-\mathrm{O} 2$ & $115.63(16)$ \\
\hline $\mathrm{C} 3-\mathrm{C} 2-\mathrm{N} 2$ & $121.35(15)$ & & \\
\hline \multicolumn{4}{|l|}{ Dihedral angles } \\
\hline $\mathrm{C} 1-\mathrm{C} 2-\mathrm{C} 3-\mathrm{N} 3$ & $178.88(16)$ & $\mathrm{C} 3-\mathrm{N} 3-\mathrm{C} 4-\mathrm{C} 5$ & $0.5(3)$ \\
\hline $\mathrm{C} 1-\mathrm{C} 2-\mathrm{C} 3-\mathrm{O} 2$ & $-1.0(3)$ & $\mathrm{C} 4-\mathrm{N} 3-\mathrm{C} 3-\mathrm{O} 2$ & $-179.79(19)$ \\
\hline $\mathrm{C} 1-\mathrm{C} 2-\mathrm{N} 2-\mathrm{C} 5$ & $-179.20(18)$ & $\mathrm{N} 1-\mathrm{C} 1-\mathrm{C} 2-\mathrm{N} 2$ & $-0.4(2)$ \\
\hline $\mathrm{C} 2-\mathrm{C} 3-\mathrm{N} 3-\mathrm{C} 4$ & $0.3(3)$ & $\mathrm{N} 2-\mathrm{C} 2-\mathrm{C} 3-\mathrm{N} 3$ & $-1.0(3)$ \\
\hline $\mathrm{C} 2-\mathrm{N} 2-\mathrm{C} 5-\mathrm{C} 4$ & $0.2(3)$ & $\mathrm{N} 2-\mathrm{C} 2-\mathrm{C} 1-\mathrm{O} 1$ & $179.23(17)$ \\
\hline $\mathrm{C} 2-\mathrm{N} 2-\mathrm{C} 5-\mathrm{F} 1$ & $-179.29(19)$ & $\mathrm{N} 2-\mathrm{C} 2-\mathrm{C} 3-\mathrm{O} 2$ & $179.15(17)$ \\
\hline $\mathrm{C} 3-\mathrm{C} 2-\mathrm{C} 1-\mathrm{N} 1$ & $179.68(16)$ & $\mathrm{N} 3-\mathrm{C} 4-\mathrm{C} 5-\mathrm{N} 2$ & $-0.9(4)$ \\
\hline $\mathrm{C} 3-\mathrm{C} 2-\mathrm{C} 1-\mathrm{O} 1$ & $-0.7(3)$ & N3-C4-C5-F1 & $178.6(2)$ \\
\hline C3-C2-N2-C5 & $0.7(3)$ & & \\
\hline
\end{tabular}

Table 2 Hydrogen and halogen bond lengths $(\AA)$ and angles $\left(^{\circ}\right)$ in the structure of favipiravir. ${ }^{\mathrm{a}}$

\begin{tabular}{lllll}
\hline $\mathrm{D}-\mathrm{X} \cdots \mathrm{A}$ & $d(\mathrm{D}-\mathrm{X})$ & $d(\mathrm{X} \cdots \mathrm{A})$ & $d(\mathrm{D} \cdots \mathrm{A})$ & $\angle(\mathrm{DXA})$ \\
\hline $\mathrm{N} 1-\mathrm{H} 1 \mathrm{~A} \cdots \mathrm{O} 1^{\# 1}$ & 0.86 & 2.06 & $2.910(2)$ & 169 \\
$\mathrm{~N} 1-\mathrm{H} 1 \mathrm{~B} \cdots \mathrm{N} 3^{\# 2}$ & 0.86 & 2.34 & $3.000(2)$ & 134 \\
$\mathrm{O} 2-\mathrm{H} 2 \cdots \mathrm{O} 1$ & 0.82 & 1.88 & $2.591(2)$ & 144 \\
$\mathrm{C} 4-\mathrm{H} 4 \cdots \mathrm{O} 1^{\# 3}$ & 0.93 & 2.61 & $3.445(3)$ & 150 \\
$\mathrm{C} 5-\mathrm{F} 1 \cdots \mathrm{F} 1-\mathrm{C} 5^{\# 4}$ & $1.339(3)$ & $3.067(3)$ & $4.317(3)$ & $154.88(17)$ \\
$\mathrm{C} 5-\mathrm{F} 1 \cdots \mathrm{F} 1-\mathrm{C5}^{\# 5}$ & $1.339(3)$ & $3.067(3)$ & $3.578(3)$ & $101.23(16)$ \\
\hline
\end{tabular}

${ }^{a}$ Symmetry transformations used to generate equivalent atoms: \#1 $1-x, 1-y,-1 / 2+z ; \# 2-1 / 2+x, 1 / 2-y,-1+z ; \# 3-3 / 2-x$, $1 / 2+y,-1 / 2+z ; \# 41-x,-y,-1 / 2+z ; \# 51-x,-y, 1 / 2+z$

enrichment ratios $E_{\mathrm{HH} / \mathrm{C} / \mathrm{N}}, E_{\mathrm{NO}}$ and $E_{\mathrm{OF}}$ are less than unity. Remaining contacts are significantly impoverished as evidenced from the corresponding enrichment ratios (Table 3).
Voids in the crystal structure of favipiravir (Fig. 6) were calculated using CrystalExplorer 17 [27]. It was found that the void volume is $66.99 \AA^{3}$ and the corresponding surface area is $271.69 \AA^{2}$. With the porosity, the calculated void volume in the crystal structure of favipiravir is about $11 \%$.

Energy frameworks have been calculated using CrystalExplorer 17 [27] to additionally analyze the overall crystal packing of favipiravir. A single-point molecular wavefunction at B3LYP/6-31G $(\mathrm{d}, \mathrm{p})$ was applied for a cluster of radius $3.8 \AA$ to perform the energy calculation (Table 4, Fig. 7) [29]. It was found that the electrostatic energy contribution either prevails over or close comparable to the dispersion energy contribution (Table 4, Fig. 7) for the molecules interacting through $\mathrm{N}-\mathrm{H} \cdots \mathrm{O}, \mathrm{N}-\mathrm{H} \cdots \mathrm{N}$ and $\mathrm{C}-\mathrm{H} \cdots \mathrm{O}$ hydrogen bonds (Fig. 2, Table 2), while for the other molecules the dispersion energy contribution is a remarkably dominant one. The overall topology of the energy distributions in the crystal structure of favipiravir was studied through the energy framework. It was established that the structure is mainly characterized by the dispersion energy framework followed by a close comparible electrostatic energy framework contribution (Fig. 8).

In addition to the energetic evaluation of the frameworks using the CrystalExplorer, we have used a higher level of theory to analyse the energetic features of the hydrogen bonds in the solid state of favipiravir. The MEP surface of favipiravir shows that this molecule is better hydrogen bond donor than acceptor (Fig. 9). The MEP maximum is located on the H1A atom of the amido $\mathrm{NH}_{2}$ group (see Fig. 2 for atom numbering scheme). The amido oxygen atom and the aromatic nitrogen atom adjacent to the phenol group present are the best hydrogen bond acceptor atoms $(-125 \mathrm{~kJ} / \mathrm{mol})$. In normal conditions, the amido oxygen atom would better hydrogen bond acceptor than the aromatic nitrogen atom. In this particular case, the oxygen atom is receiving charge from the phenolic hydrogen atom, thus diminishing its negative charge. The oxygen atom of the phenol group is also a good hydrogen bond acceptor $(-114 \mathrm{~kJ} / \mathrm{mol})$. However, the other aromatic nitrogen atom of the pyrazine ring and the fluorine atom present modest MEP values and they are much worse hydrogen bond acceptor sites. In fact, the small MEP value at the fluorine atom explains the formation of F...F contacts (Fig. 2), since these interactions are dominated by dispersion and polarization effects that compensate the repulsive electrostatic forces.

We have analysed using a combination of QTAIM and NCIplot computational tools the hydrogen bonds in favipiravir. We have analysed the pentameric cluster, where a 
Fig. 3 (top) Crystal packing of favipiravir. Color code: $\mathrm{H}=$ black, $\mathrm{C}=$ gold, $\mathrm{N}=$ blue, $\mathrm{O}=$ red, $\mathrm{F}=$ green; $\mathrm{N}-\mathrm{H} \cdots \mathrm{O} / \mathrm{N}$, $\mathrm{O} / \mathrm{C}-\mathrm{H} \cdots \mathrm{O}$ and $\mathrm{C}-\mathrm{F} \cdots \mathrm{F}-\mathrm{C}$ interactions $=$ dashed cyan line (bottom) A simplified network of favipiravir, constructed from intermolecular $\mathrm{N}-\mathrm{H} \cdots \mathrm{O}$, $\mathrm{N}-\mathrm{H} \cdots \mathrm{N}$ and $\mathrm{C}-\mathrm{H} \cdots \mathrm{O}$ hydrogen bonds, with the uninodal 4-connected zst topology defined by the point symbol of $\left(6^{5} \cdot 8\right)$. Color code: favipiravir $=$ magenta
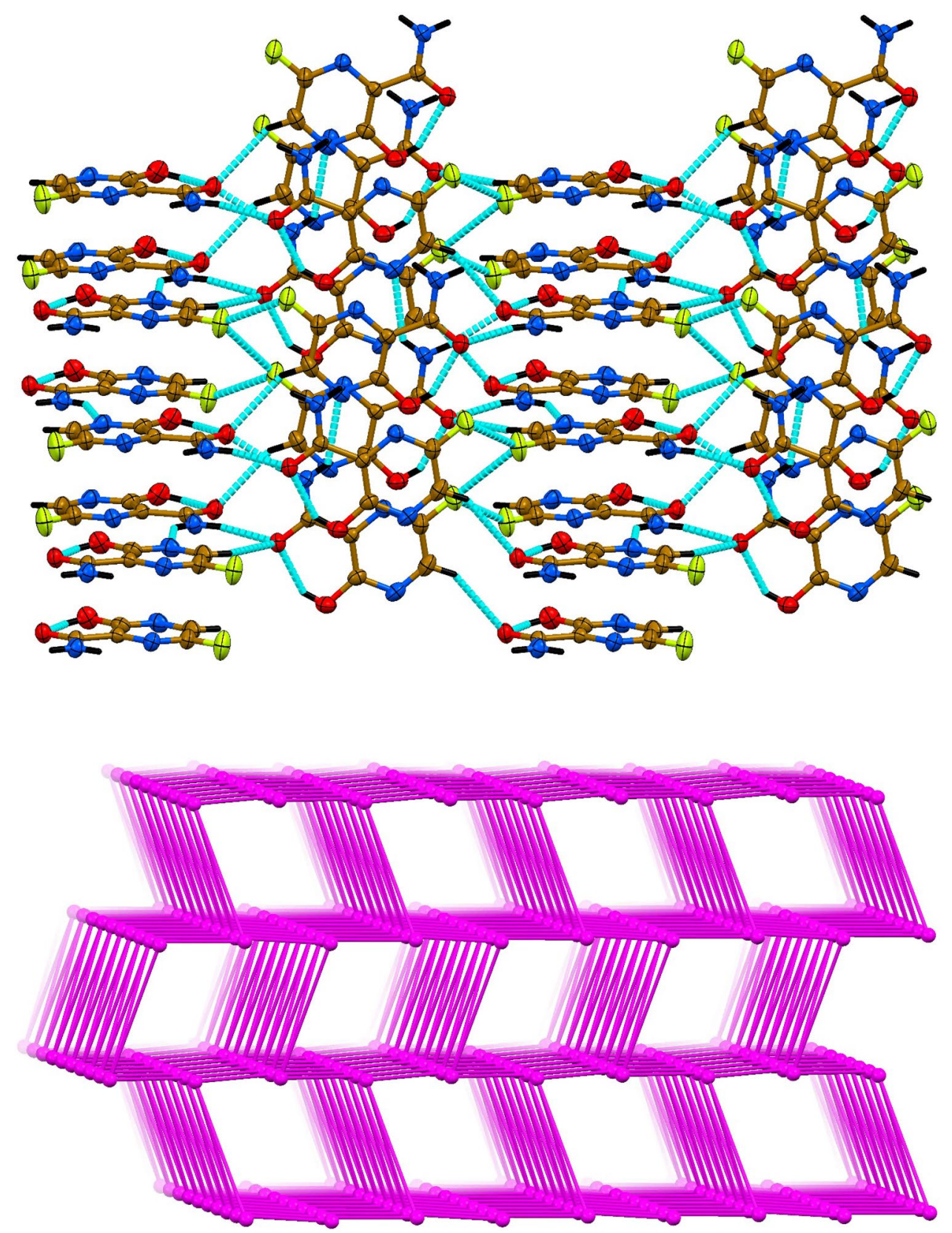

network of hydrogen bonds around the central molecule is formed (Fig. 10). Both hydrogen atoms of the $\mathrm{NH}_{2}$ group (the most electron deficient atoms) form hydrogen bonds with the most electron rich oxygen and nitrogen atoms of favipiravir, in excellent agreement with the MEP surface analysis. Each hydrogen bond is characterized by a bond critical point (represented as a red sphere) and bond path interconnecting the hydrogen and oxygen or nitrogen atoms.
The NCIplot index analysis reveals the strong nature of these hydrogen bonds, since they are characterized by blue isosurfaces. The combined QTAIM/NCIplot analysis also shows the existence of a $\mathrm{C}-\mathrm{H} \cdots \mathrm{O}$ interaction characterized by a bond critical point denoted as "f" and bond path connecting the interacting atoms. The binding energy of the pentameric assembly is large and negative $(-102.8 \mathrm{~kJ} / \mathrm{mol})$ due to the 

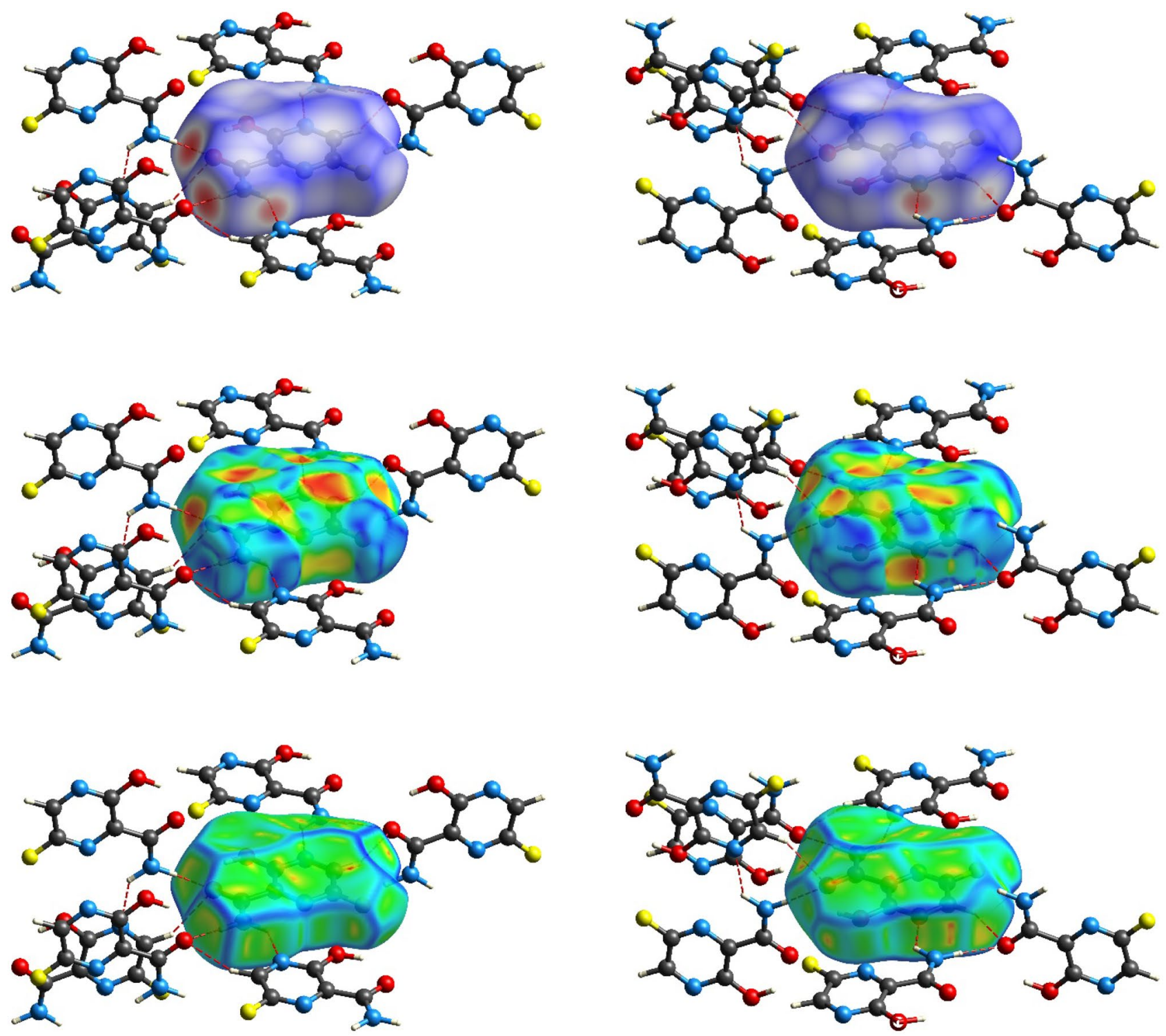

Fig. 4 Molecular Hirshfeld surfaces of favipiravir (top, middle, bottom denote normalized distance $d_{\text {norm }}$, shape index and curvedness, respectively). Right column views are $180^{\circ}$ rotation of the left column views within the plane of a sheet
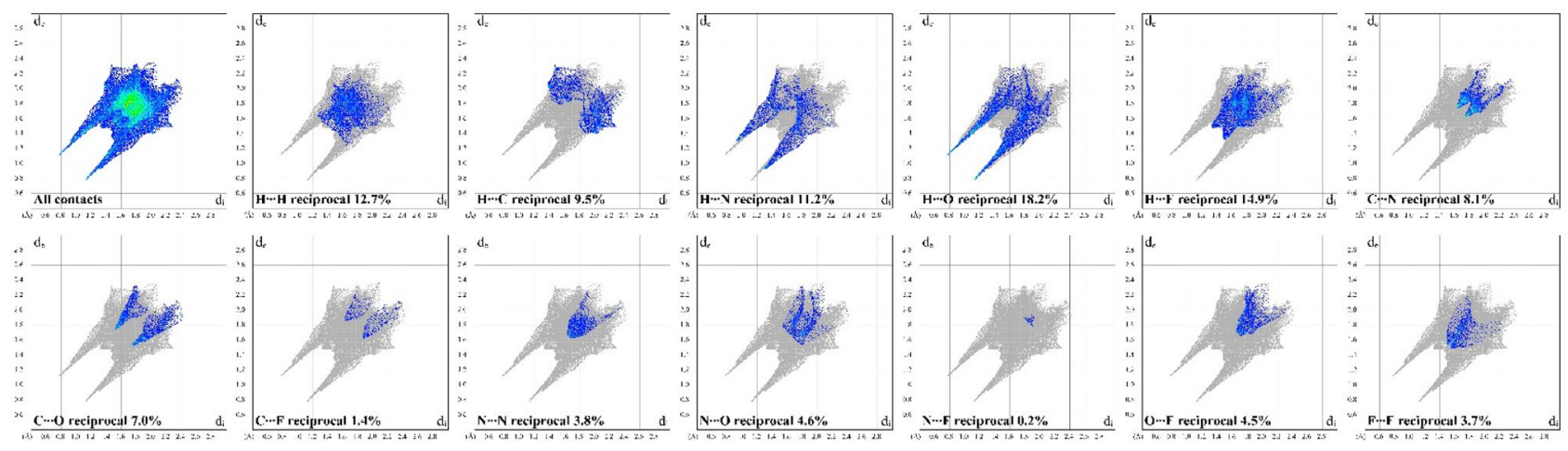

Fig. 5 2D and decomposed 2D fingerprint plots of observed contacts for favipiravir 
Table 3 Hirshfeld contact surfaces and derived "random contacts" and "enrichment ratios" for favipiravir

\begin{tabular}{lccccc}
\hline & $\mathrm{H}$ & $\mathrm{C}$ & $\mathrm{N}$ & $\mathrm{O}$ & $\mathrm{F}$ \\
\hline \multicolumn{2}{l}{ Contacts $(C, \%)^{\mathrm{a}}$} & & & & \\
$\mathrm{H}$ & 12.8 & - & - & - & - \\
$\mathrm{C}$ & 9.5 & 0.0 & - & - & - \\
$\mathrm{N}$ & 11.2 & 8.1 & 3.8 & - & - \\
$\mathrm{O}$ & 18.3 & 7.0 & 4.6 & 0.0 & - \\
$\mathrm{F}$ & 14.9 & 1.4 & 0.2 & 4.5 & 3.7 \\
\multicolumn{2}{l}{ Surface $(S, \%)$} & & & & \\
& 39.8 & 13.0 & 15.9 & 17.2 & 14.2 \\
Random contacts $(R, \%)$ & & & & \\
$\mathrm{H}$ & 15.8 & - & - & - & - \\
$\mathrm{C}$ & 10.3 & 1.7 & - & - & - \\
$\mathrm{N}$ & 12.7 & 4.1 & 2.5 & - & - \\
$\mathrm{O}$ & 13.7 & 4.5 & 5.5 & 3.0 & - \\
$\mathrm{F}$ & 11.3 & 3.7 & 4.5 & 4.9 & 2.0 \\
Enrichment $($ E) & & & & & \\
$\mathrm{H}$ & 0.81 & - & - & - & - \\
$\mathrm{C}$ & 0.92 & 0.00 & - & - & - \\
$\mathrm{N}$ & 0.88 & 1.98 & 1.52 & - & - \\
$\mathrm{O}$ & 1.34 & 1.56 & 0.84 & 0.00 & - \\
$\mathrm{F}$ & 1.32 & 0.38 & 0.04 & 0.92 & 1.85 \\
\hline
\end{tabular}

${ }^{\mathrm{a}}$ Values are obtained from CrystalExplorer 17 [27], ${ }^{\mathrm{b}}$ The "enrichment ratios" were not computed when the "random contacts" were lower than $0.9 \%$, as they are not meaningful [28]

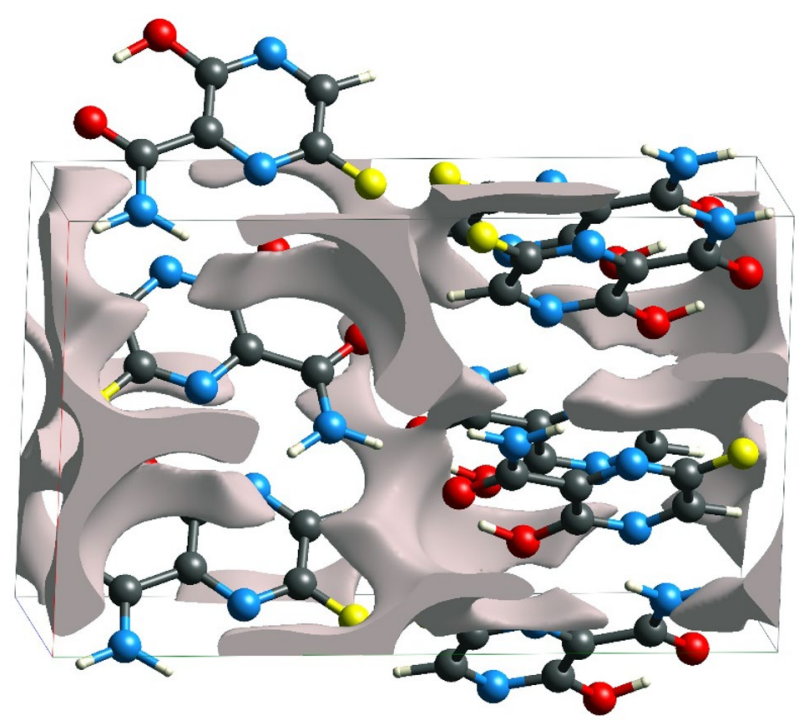

Fig. 6 Void plot for favipiravir (results under 0.002 a. u. isovalue) formation of four strong hydrogen bonds and also a $\pi \cdots \pi$ interaction between two favipiravir units. Latter interaction is characterized by four bond critical points and bond paths that interconnect both rings. Moreover, the $\pi \cdots \pi$ interaction is further characterized by an extended and green NCIplot isosurface located between both $\pi$-systems.

Since we are interested in the evaluation of the energy of each of the hydrogen bonds that form the pentameric cluster, the formation energy of each hydrogen bond has been calculated by using the kinetic energy density $\left(V_{r}\right)$ predictor, as proposed in the literature $\left(E_{\mathrm{HB}}=0.5 \times V_{r}\right)$ [30]. The $V_{r}$ value at CPs labelled in Fig. 10 are gathered in Table 5.

The intramolecular hydrogen bond is very strong $(-40.4 \mathrm{kcal} / \mathrm{mol})$ due to the strong acidity of the phenol group that is enhanced due to presence of the para-fluorine substituent with respect to the hydroxyl group. Moreover, the oxygen atom of the amido group is also a good hydrogen bond acceptor. The intermolecular $\mathrm{N}-\mathrm{H}$... O hydrogen bonds that correspond to the critical points labelled as "d" and "e" are also strong because the hydrogen bond donor and acceptor groups correspond to the maximum and minimum MEP regions of the molecule, respectively. The $\mathrm{N}-\mathrm{H} \cdots \mathrm{N}$ hydrogen bonds (critical points labelled as "b" and "c") are weaker in agreement with the MEP values indicated in Fig. 9. Finally, the $\mathrm{C}-\mathrm{H} \cdots \mathrm{O}$ bond corresponds to the weakest hydrogen bond $(-4.5 \mathrm{~kJ} / \mathrm{mol})$.

\section{Conclusions}

In summary, we report detailed structural studies of favipiravir, which is now used as a drug for COVID-19 treatment.

According to the single crystal X-ray diffraction data, the asymmetric unit of favipiravir comprises one molecule, stabilized by an intramolecular $\mathrm{O}-\mathrm{H} \cdots \mathrm{O}$ hydrogen bond, formed between the hydroxyl hydrogen atom and carbonyl oxygen atom, yielding a six-membered pseudo-aromatic ring. The aromaticity index of this pseudo-aromatic ring was found to be 0.748 , while the same index for the pyrazine ring in favipiravir was found to be 0.954 . The crystal structure of favipiravir is additionally stabilized by intermolecular $\mathrm{N}-\mathrm{H} \cdots \mathrm{O}, \mathrm{N}-\mathrm{H} \cdots \mathrm{N}$ and $\mathrm{C}-\mathrm{H} \cdots \mathrm{O}$ hydrogen bonds, yielding a 3D supramolecular framework with a zst topology defined 
Table 4 Interaction energies $(\mathrm{kJ} / \mathrm{mol})$ calculated with the B3LYP/6-31G(d,p) energy model for the crystal structure of favipiravir (values in parenthesis are obtained after normalizing to $100 \%$ the sum of the attractive energy contributions)

\begin{tabular}{llllllll}
\hline$N^{\mathrm{a}}$ & symmetry operation & $R$ & $E_{\text {ele }}^{\mathrm{b}}$ & $E_{\mathrm{pol}}^{\mathrm{b}}$ & $E_{\text {dis }}^{\mathrm{b}}$ & $E_{\text {rep }}$ & $E_{\text {tot }}^{\mathrm{b}}$ \\
\hline 2 & $-x,-y, z+1 / 2$ & 8.25 & $-0.9(15.5)$ & $-0.1(1.7)$ & $-4.8(82.8)$ & 1.4 & -4.3 \\
2 & $-x+1 / 2, y+1 / 2, z+1 / 2$ & 8.03 & $-4.4(39.3)$ & $-1.3(11.6)$ & $-5.5(49.1)$ & 5.5 & -7.0 \\
2 & $-x+1 / 2, y+1 / 2, z+1 / 2$ & 8.03 & $-0.5(11.4)$ & $-0.1(2.3)$ & $-3.8(86.3)$ & 0.3 & -3.8 \\
2 & $x, y, z$ & 4.69 & $-3.7(13.7)$ & $-1.3(4.8)$ & $-22.1(81.5)$ & 8.9 & -18.6 \\
2 & $-x,-y, z+1 / 2$ & 7.98 & $-30.3(69.0)$ & $-6.4(14.6)$ & $-7.2(16.4)$ & 30.9 & -24.0 \\
2 & $x+1 / 2,-y+1 / 2, z$ & 6.54 & $-15.7(48.2)$ & $-5.4(16.6)$ & $-11.5(35.2)$ & 20.8 & -17.8 \\
2 & $x+1 / 2,-y+1 / 2, z$ & 4.56 & $-2.9(10.7)$ & $-1.3(4.8)$ & $-22.8(84.5)$ & 10.4 & -17.5 \\
\hline
\end{tabular}

${ }^{a} N$ is the number of molecules with an $R$ molecular centroid-to-centroid distance $(\AA)$; colour codes in the first column are referenced to Fig. 7 ${ }^{\mathrm{b}} E_{\text {ele }}$ is the electrostatic energy, $E_{\mathrm{pol}}$ is the polarization energy, $E_{\mathrm{dis}}$ is the dispersion energy, $E_{\mathrm{rep}}$ is the exchange-repulsion energy, $k$ values are scale factors; $E_{\text {tot }}=k_{\text {ele }} \times E_{\text {ele }}+k_{\text {pol }} \times E_{\text {pol }}+k_{\text {dis }} \times E_{\text {dis }}+k_{\text {rep }} \times E_{\text {rep }}=1.057 \times E_{\text {ele }}+0.740 \times E_{\text {pol }}+0.871 \times E_{\text {dis }}+0.618 \times E_{\text {rep }}[29]$

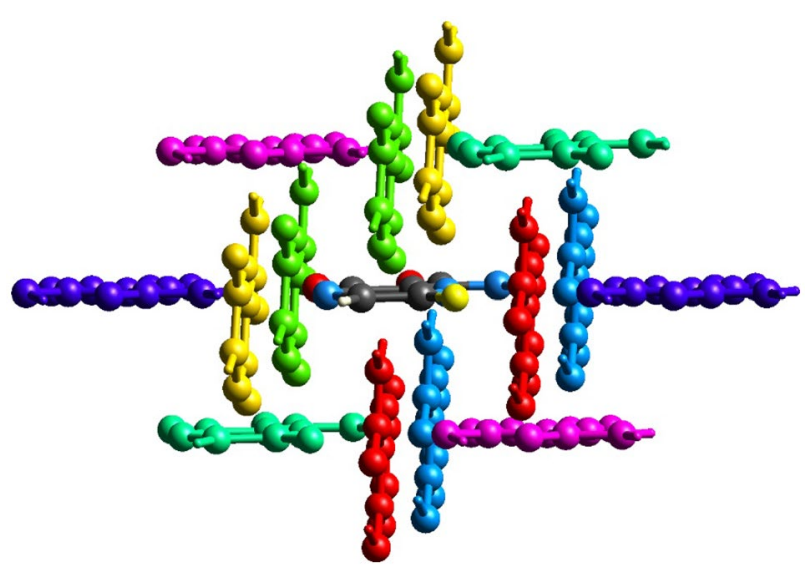

Fig. 7 The colour-coded interaction mapping within $3.8 \AA$ of the centring molecule in the crystal structure of favipiravir, calculated from a single-point molecular wavefunction at B3LYP/6-31G(d,p) by the point symbol of $\left(6^{5} \cdot 8\right)$. The crystal structure of favipiravir is further stabilized by weak $\mathrm{C}-\mathrm{F} \cdots \mathrm{F}-\mathrm{C}$ intermolecular type II dihalogen interactions, yielding a 1D supramolecular polymeric chain.

It was established that more than $80 \%$ of the total Hirshfeld surface area for favipiravir is occupied by $\mathrm{H} \cdots \mathrm{H} / \mathrm{C} / \mathrm{N} /$ $\mathrm{O} / \mathrm{F}$ and $\mathrm{C} \cdots \mathrm{N} / \mathrm{O}$ contacts. Energy frameworks have been calculated to additionally analyse the overall crystal packing. It was established that the structure of favipiravir is mainly characterized by the dispersion energy framework followed by the less significant electrostatic energy framework contribution. Finally, we hope that the herein reported result will be of value for crystal engineering community to further study the chemistry of favipiravir. The QTAIM energetic analysis can be useful to develop scoring functions for docking studies of this drug or for the fine tuning of existent force fields.
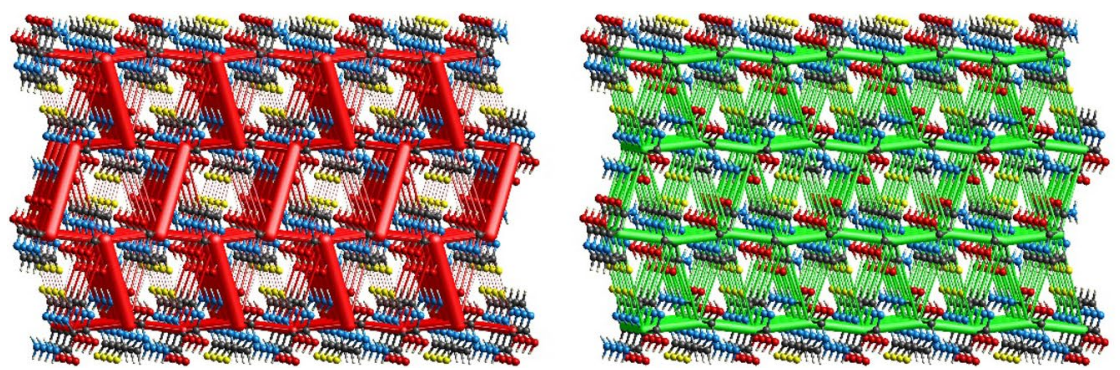

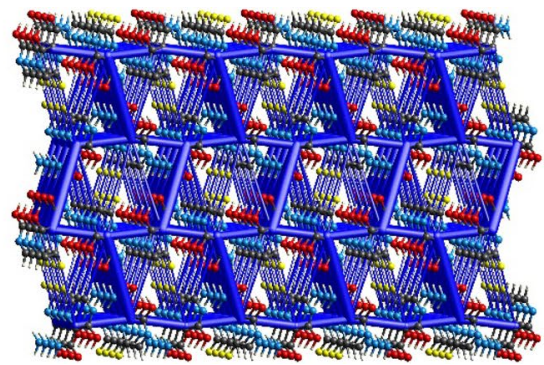

Fig. 8 Energy frameworks calculated for the crystal structure of favipiravir, showing the (left) electrostatic potential force, (middle) dispersion force and (right) total energy diagrams. The cylindrical radii are proportional to the relative strength of the corresponding energies and they were adjusted to the same scale factor of 200 within $4 \times 2 \times 4$ unit cells 


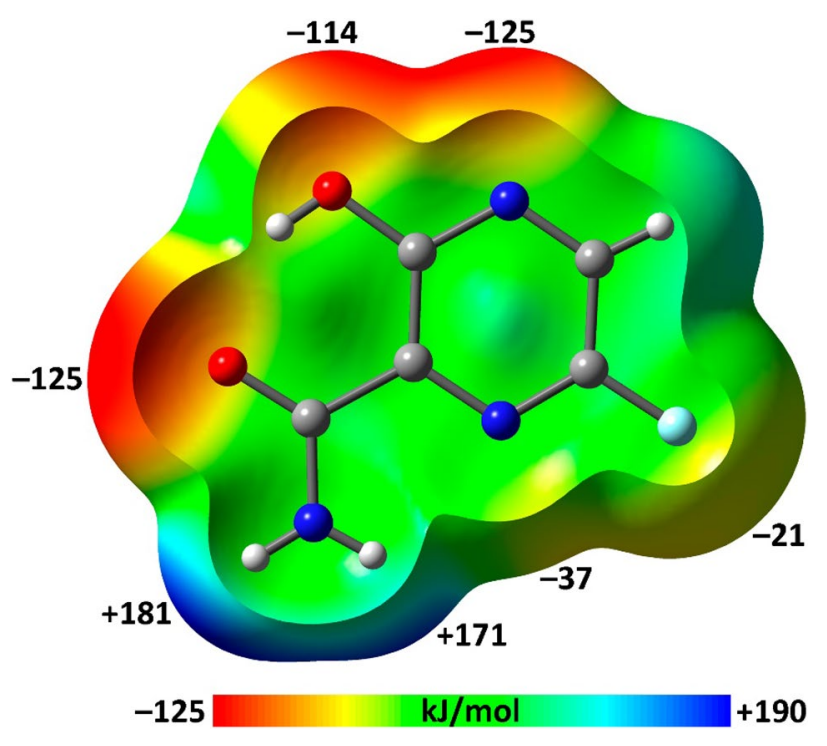

Table 5 Values of $\rho(r)$, its Laplacian, the kinetic energy density and the hydrogen bond energy corresponding to the bond critical points labelled in Fig. 10

\begin{tabular}{lllll}
\hline & $\rho($ r), a.u. & $\nabla^{2} \rho($ r), a.u. & $\mathrm{V}(\mathrm{r})$, a.u. & $E_{\mathrm{HB}}, \mathrm{kJ} / \mathrm{mol}$ \\
\hline $\mathrm{a}$ & 0.0316 & 0.1358 & -0.0308 & -40.4 \\
$\mathrm{~b}$ & 0.0132 & 0.0529 & -0.0079 & -10.4 \\
$\mathrm{c}$ & 0.0131 & 0.0527 & -0.0080 & -10.5 \\
$\mathrm{~d}$ & 0.0178 & 0.0835 & -0.0128 & -16.8 \\
$\mathrm{e}$ & 0.0178 & 0.0831 & -0.0127 & -16.7 \\
$\mathrm{f}$ & 0.0062 & 0.0240 & -0.0034 & -4.5 \\
\hline
\end{tabular}

Fig. 9 MEP surface of favipiravir (isosurface 0.01 a.u.) at the PBE0D3/def2-TZVP level of theory. The energies at selected points of the surface are given

Fig. 10 Combined QTAIM (bond and ring critical points are in red and yellow, respectively) and NCIplot analyses of the pentameric cluster of favipiravir

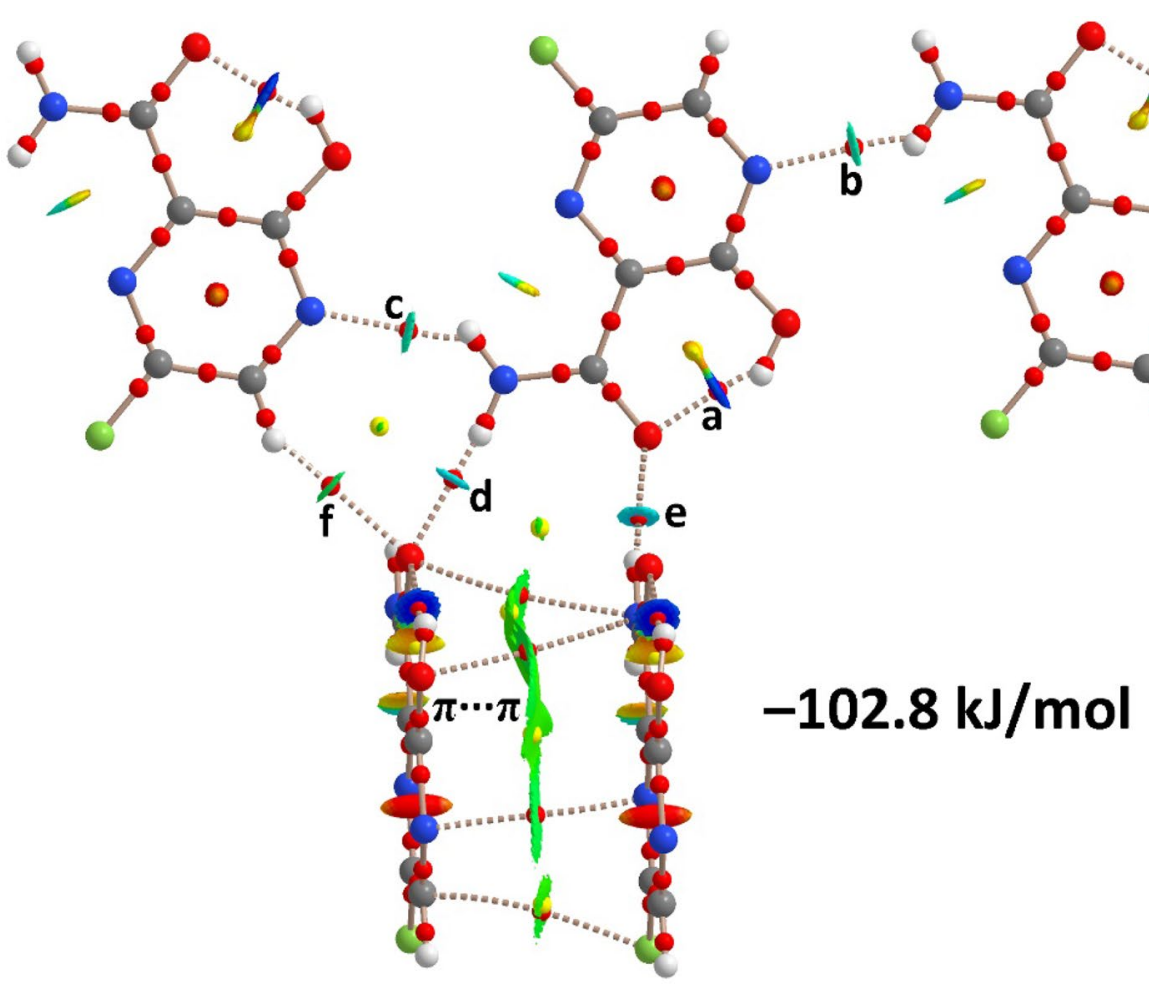


Acknowledgements A. Frontera thanks the MICIU/AEI of Spain (project CTQ2017-85821-R FEDER funds) for financial support.

\section{Declarations}

Conflict of interest The authors declare no conflicts of interest.

\section{References}

1. Y. Furuta, K. Takahashi, K. Shiraki, K. Sakamoto, D.F. Smee, D.L. Barnard, B.B. Gowen, J.G. Julander, J.D. Morrey, Antivir. Res. 82, 95-102 (2009)

2. Y. Furuta, T. Komeno, T. Nakamura, Proc. Jpn. Acad. Ser. B 93, 449-463 (2017)

3. K. Shiraki, T. Daikoku, Pharmacol. Ther. 209, 107512 (2020)

4. L. Dong, S. Hu, J. Gao, Drug. Discov. Ther. 14, 58-60 (2020)

5. W. Ahsan, S. Javed, M.A. Bratty, H.A. Alhazmi, A. Najmi, Drug. Discov. Ther. 14, 67-72 (2020)

6. C.R. Groom, I.J. Bruno, M.P. Lightfoot, S.C. Ward, Acta Crystallogr. B72, 171-179 (2016)

7. F. Shi, Z. Li, L. Kong, Y. Xie, T. Zhang, W. Xu, Drug. Discov. Ther. 8, 117-120 (2014)

8. M.J. Frisch, G.W. Trucks, H.B. Schlegel, G.E. Scuseria, M.A. Robb, J.R. Cheeseman, G. Scalmani, V. Barone, G.A. Petersson, H. Nakatsuji, X. Li, M. Caricato, A. Marenich, J. Bloino, B.G. Janesko, R. Gomperts, B. Mennucci, H.P. Hratchian, J.V. Ortiz, A.F. Izmaylov, J.L. Sonnenberg, D. Williams-Young, F. Ding, F. Lipparini, F. Egidi, J. Goings, B. Peng, A. Petrone, T. Henderson, D. Ranasinghe, V.G. Zakrzewski, J. Gao, N. Rega, G. Zheng, W. Liang, M. Hada, M. Ehara, K. Toyota, R. Fukuda, J. Hasegawa, M. Ishida, T. Nakajima, Y. Honda, O. Kitao, H. Nakai, T. Vreven, K. Throssell, J.A. Montgomery, Jr., J.E. Peralta, F. Ogliaro, M. Bearpark, J.J. Heyd, E. Brothers, K.N. Kudin, V.N. Staroverov, T. Keith, R. Kobayashi, J. Normand, K. Raghavachari, A. Rendell, J.C. Burant, S.S. Iyengar, J. Tomasi, M. Cossi, J.M. Millam, M. Klene, C. Adamo, R. Cammi, J.W. Ochterski, R.L. Martin, K. Morokuma, O. Farkas, J.B. Foresman, D.J. Fox, Gaussian 16 (Revision A.03), Gaussian Inc., Wallingford CT, 2016

9. S.B. Boys, F. Bernardi, Mol. Phys. 19, 553-556 (1970)
10. S. Grimme, J. Antony, S. Ehrlich, H. Krieg, Chem. Phys. 132, 154104 (2010)

11. P. Manna, S.K. Seth, M. Mitra, S. Ray Choudhury, A. Bauzá, A. Frontera, S. Mukhopadhyay, Cryst. Growth Des. 14, 5812-5821 (2014)

12. M. Mirzaei, H. Eshtiagh-Hosseini, Z. Bolouri, Z. Rahmati, A. Esmaeilzadeh, A. Bauza, P. Ballester, M. Barceló-Oliver, J.T. Mague, B. Notash, A. Frontera, Cryst. Growth Des. 15, 13511361 (2015)

13. R.F.W. Bader, J. Phys. Chem. A 102, 7314-7323 (1998)

14. J. Contreras-Garcia, E. Johnson, S. Keinan, R. Chaudret, J.-P. Piquemal, D. Beratan, W. Yang, J. Chem. Theor. Comp. 7, 625$632(2011)$

15. T.A. Keith, AIMAll (Version 19.02.13), TK Gristmill Software, Overland Park KS, USA, 2019 (aim.tkgristmill.com)

16. T.M. Krygowski, H. Szatylowicz, O.A. Stasyuk, J. Dominikowska, M. Palusiak, Chem. Rev. 114, 6383-6422 (2014)

17. L. Sobczyk, S.J. Grabowski, T.M. Krygowski, Chem. Rev. 105, 3513-3560 (2005)

18. C.P. Frizzo, M.A.P. Martins, Struct. Chem. 23, 375-380 (2012)

19. T.M. Krygowski, K. Woźniak, R. Anulewicz, D. Pawlak, W. Kolodziejski, E. Grech, A. Szady, J. Phys. Chem. A 101, 9399 9404 (1997)

20. V.A. Blatov, A.P. Shevchenko, D.M. Proserpio, Cryst. Growth Des. 14, 3576-3586 (2014)

21. L.C. Gilday, S.W. Robinson, T.A. Barendt, M.J. Langton, B.R. Mullaney, P.D. Beer, Chem. Rev. 115, 7118-7195 (2015)

22. H. Wang, W. Wang, W.J. Jin, Chem. Rev. 116, 5072-5104 (2016)

23. M.H. Kolář, P. Hobza, Chem. Rev. 116, 5155-5187 (2016)

24. A. Bondi, J. Phys. Chem. 68, 441-451 (1964)

25. M.A. Spackman, D. Jayatilaka, CrystEngComm 11, 19-32 (2009)

26. M.A. Spackman, J.J. McKinnon, CrystEngComm 4, 378-392 (2002)

27. M.J. Turner, J.J. McKinnon, S.K. Wolff, D.J. Grimwood, P.R. Spackman, D. Jayatilaka, M.A. Spackman, CrystalExplorer17, University of Western Australia, 2017. http://hirshfeldsurface.net

28. C. Jelsch, K. Ejsmont, L. Huder, IUCrJ 1, 119-128 (2014)

29. C.F. Mackenzie, P.R. Spackman, D. Jayatilaka, M.A. Spackman, IUCrJ 4, 575-587 (2017)

30. E. Espinosa, E. Molins, C. Lecomte, Chem. Phys. Lett. 285, 170173 (1998) 